\title{
STUDYING THE INFLUENCE OF VARIABLE SUB-LOT SIZES ON HYBRID FLOW- SHOP WITH UNRELATED ELIGIBLE PARALLEL MACHINES
}

\author{
ENAS AHMED ZAKY ${ }^{1 *}$, TAMER A. MOHAMED ${ }^{2} \&$ AND SAYED M. TAHAA ${ }^{3}$ \\ ${ }^{I}$ Mechanical Design and Production Engineering Dept., Faculty of Engineering, Minia University, Minia, Egypt \\ ${ }^{2}$ Mechanical Engineering Dept., The British University in Egypt, Cairo, Cairo, Egypt
}

${ }^{3}$ Mechanical Design and Production Engineering Dept., Faculty of Engineering, Minia University, Minia, Egypt

ABSTRACT
The manufacturing systems have many configurations. The hybrid flow-shop configuration is one of the most
manufacturing systems that have many applications. One of these applications is the metal nails factory. This
system consists of different stages and each stage has different parallel machines. The machines are unrelated
parallel or multi-machines. The speed of the machines can be uniform or variable. With respect to the jobs, the
stream of material flows in the same direction among the stages and the jobs can be split into batches to utilize the
machines. In this paper, a system of hybrid flow-shop of machines, which are unrelated, have variable speed, and
have eligibility constraints is considered. The jobs have variable sub-lot sizes. The variability of the sub-lots sizes
can be achieved by splitting the sub-lots into smaller sub-lots from one stage to another. A real case for this system
is solved using a non-linear mixed-integer programming model and the sub-lot size and schedule that minimize the
overall make-span are achieved. The model is compared to four benchmarking cases studies. The results show the
proposed model is better than the benchmarking cases studies. The relative percentage index that is used to
compare the results is up to $47 \%$.
KEYWORDS: HFS, multimachine, HFSP

Received: Dec 21, 2020; Accepted: Jan 11, 2021; Published: Jan 19, 2021; Paper Id.: IJMPERDFEB20215

\section{INTRODUCTION}

The hybrid flow-shop (HFS) system is considered in a wide range of applications in manufacturing fields. HFS has made its popular nature for its application in modern electronic industries, including semi-conductors' fabrication, printed circuits board manufacturing, and also in traditional manufacturing fields like parts of car manufacturing and steel and metal nails manufacturing. There are three configurations of HFS, these are multimachine HFS in which the job requires to be processed at the same machine many times; uniform HFS in which the machines' speed has lower and upper bounds and non-identical parallel HFS in which the machines` speeds are varied. [1]proved that the HFS with only two stages have multi-identical machines that are NP-hard. NP-hard problems are with no known polynomial algorithm so that the time to find a solution grows exponentially with the problem size even in the case of two stages. A hybrid flow shop with lot streaming means splitting jobs into small sub-lots. Batching occurs only if setup costs or times are not negligible, and several jobs of the same product type have to be produced. It is also used when there are limited containers for jobs. There are three problems of HFS with batching. The problem of lot streaming which is to determine the number of sub-lots; the problem of determining the sub-lot size; and finally, the problem of sub-lot sequence and job sequence with an objective minimization of 
$\mathrm{C}_{\max }$. Cheng et al. (2013) [2] showed many applications of lot streaming, like increasing velocity of production flow "lean thinking"; supply chain coordination; mass customization in the semiconductor, and electronics manufacturing and services industries. Truscott W (1986) [3] showed the advantages of lot streaming as following:

Reduction of production leads time.

Reduction of WIP inventory and associated costs.

Reduction of inter in storage and space requirement.

Reduction of material handling.

Improve services to the customer.

Possibility of overlapping various operations of the same job.

There are many researchers who prepared review studies for the HFS system. Ribas et al. (2010), [4] reviewed 164 types of researches of HFS based on job constraints and solution approaches. Their study was helpful in guiding the researchers to focus on uncovered points. Ruiz and Vázquez-Rodríguez (2010) [5] in their review stated that the researchers studied the configuration of the machine as there are about $83.72 \%$ identical machines, $4.66 \%$ are uniform machines, and $11.62 \%$ parallel machines. They also mentioned that the make-span has the highest studied objective by $60 \%$ of the researches. Lee et al. (2019) [6] mentioned that the researchers studied the configuration of the machine with unrelated parallel machines by $14 \%$ and exact machines by $8 \%$.

There are many heuristics used to solve the problem of HFS with or without lot-streaming. HFS without lot streaming, many researchers have studied the different configurations of HFS. Fattahi et al. (2014) [7] studied the hybrid flow shop scheduling problem (HFSP) with assembly operations. In their problem, many products of the same kind are produced. Each product is assembled using a set of several parts. At first, the parts are produced in a hybrid flow shop and then they are assembled in an assembly stage to produce products. They used branch and bound to solve the problem and compared the results with different lower bound and found that their algorithm has just $1.13 \%$ deviation from the lower bound of the solution in total. Paul and Azeem (2010) [8] used Fuzzy logic to solve the problem of minimization of workin-process inventory in the HFS system. This objective has its importance due to the space of the workshop if it is small. Low et al,. (2008) [9] solved a problem of HFS with unrelated machines and two stages with respect to the minimization of make-span. They have used modified Johnson's rule and the First-Fit rule to solve the problem and their experiments give the best results compared to random methods. Choong and Alias (2011) [10] solved the problem of minimization of the make-span of HFS with two methods. They solved the problem with the combination of particle swarm optimization (PSO) with simulated annealing (SA) and tabu search (TS) respectively and compared the solution with Memetic algorithms. The results showed the Memetic algorithms have better results than the combination.

HFS with lot streaming has been studied extensively as well in literature. Cheng et al. (2013) [2] reviewed a lot streaming in all types of manufacturing configurations. They classified the sub-lot types into three types: variable sub-lot, consistent sub-lot, and equal sub-lot. As for the sub-lot size, there are two types: continues and discrete. There are two types of batches: parallel batches that assume the machines in the same stage are able to process the number of operations simultaneously and serial batches which means that the number of jobs within the same batch is processed sequentially. 
Saluja and Jain (2014) [11] used a genetic algorithm to study the effect of lot streaming on make-span and mentioned that it increases the make-span minimization in an identical parallel machine for a flexible flow shop. $\tilde{A}$ and Beheshti-nia (2009) [12] studied the uniform machines at the HFS system with parallel batches and assumed that the setup time and transportation time are zero. They solved the NP-hard problem with 3 different heuristics and compared them with 3D genetic algorithm. They found that the 3D GA results indicate its superiority to the other heuristics. Costa et al. (2014) [13] showed the problem of HFS with parallel and eligible machines and solved it with a genetic algorithm. The batches were identical and they compared their proposed GA with different published algorithms and found that their algorithm is the best. Li et al. (2015) [14] stated that the problem of HFS consisting of multi-stages. All stages except one have non-identical and parallel machines with one batch. The different stage is composed of multiple batch processing machines. The objective of all stages is to minimize both make-span and maximum tardiness. They purposed a heuristicsearch genetic algorithm and compared it with the composition of assignment rules and sequence rules for machines to process the parts and batch formulation rules. They found that their heuristic approach is better than other heuristics based on the composed rules. Nejati et al. (2014) [15] have solved a problem of job lot streaming HFS having identical parallel machines with constraints of work-in-process jobs, sequence-dependent setup time and work shift. They used both genetic algorithm and simulated annealing and found that GA is better than the SA in performance. Lalitha et al. (2017) [16] studied a system consists of one machine at a stage before the final stage and many machines at the final stage. They solved the system with lingo solver but it takes a long time in large problems so they used a genetic algorithm to overcome this deficiency.

Naderi et al. (2010) [17] studied the multi-machines HFS system with independent setup time. They used two algorithms to solve the problem; dynamic dispatching rule heuristic, and an iterated local search metaheuristic. The iterated local search meta-heuristic is simple to code and has fewer operators and parameters; yet surprisingly shows good performance in many scenarios. Naderi et al. (2014) [18] modeled the problem of HFS with four different mixed-integer linear programming models and compared the results with the purposed particle swarm optimization algorithm. Their algorithm showed better results when compared to others.

Cheng and Sarin (2013) [2] studied a system of two stages lot streaming which consists of one machine at the first stage and two identical machines at the second stage. There were 4 heuristics that were as following: the first was studying lot streaming for the first stage and arrange it by longest process time, the second was studying lot streaming for the first stage and arrange it by shortest process time, the third was studying lot streaming for the second stage and arrange it by shortest process time, and the fourth was studying lot streaming for the second stage and arrange it by shortest process time. Uetake et al. (1995) [19] studied that HFS system with two stages and lot streaming. The first stage has one machine and the second has multi-process lines. They studied two dispatching rules on three measurements of performance. They found that the ratio rule is the best performance on make-span, the longest process time rule is best to regard to work at the process level. They found also that the optimum lot size is affected by operating conditions like setup time and process runlength. Wang et al. (2012) [20] solved the problem of two stages HFS with the first stage has serial batches and the second has parallel batches. They also considered the eligibility of machines and release time as constraints. Zhang et al. (2005) [21] calculated the lower bound to solve the problem of lot streaming HFS with two stages with respect to the objective of minimization of the mean completion time. The first stage has parallel identical machines and the second stage has only one machine. Naderi and Yazdani (2014) considered the problem of HFS with lot streaming and sequence-dependent set up time and solved it by mixed-integer linear programming. They used the bee colony algorithm and compared their 
algorithm with different four mixed-integer linear programming models and found that their purposed algorithm is outperforming the others.

Shahvari and Logendran (2018) [22] studied the effect of labor learning on the performance of jobs in the HFS with lot streaming systems with respect to the objective of minimizing the weighted sum of the total weighted completion time and total weighted tardiness simultaneously. They used hybridization of local search and population-based to solve the problem and analyzed the effect of lot streaming on the performance.

Zhang et al. (2017) [23]used a modified migrating bird's optimization algorithm to solve a problem of lot streaming HSF with identical machines. They stated that the sub-lots of different jobs cannot be intermingled.

Voß and Witt (2007) [24] considered a real case multi-mode multi-project scheduling problem to schedule 300000 jobs with batching on 16 production stages to minimize the weighted tardiness. This research is considered from a few searches that deal with real application in the steel industry. They developed two schemes to generate schedules with dispatching rules to form batches. These are a serial generation scheme and a parallel generation scheme.

There are many priority rules that are used to assign the batches on different machines. Hunsucker and Shah (1991) [25] compared 6 priority rules: first in first out; last in last out; shortest process time; longest process time; most work remaining first; and least work remaining first to solve a problem of flow shop with multiple identical machines at only one stage. They used simulation and found that the shortest process time is the most effective priority rule to minimize the make-span, mean flow time and maximum flow time.

However, Li et al. (2014) [14] identified the assignment rules as the following: first available machines; least utilization machines; most available machines; shortest process time; earliest finish time; and the sequence rules as: first in first out; time in shop; shortest process time; shortest remaining process time; largest estimation flow time; smallest processing time ratio; earliest due date; minimum slack; critical ratio; and weighted shortest processing time while batch formulation rules as shortest process time; earliest due date; and first in first out.

As shown in the literature review, most of them dealt with identical machines and identical sub-lot sizes. The main contribution of this research is that it deals with variable sub-lot sizes for unrelated parallel eligible machines. This case is found in real manufacturing systems like steel manufacturing systems and metal nails manufacturing. The mixedinteger nonlinear programming model that is developed to solve the HFS problem for parallel unrelated machines with variable sub-lot sizes is shown in Section 2. The rest of this paper is arranged as follows: Section 3 illustrates the application of the proposed model in a metal nails manufacturing company as a real case study. Section 4 shows the comparative study with the four benchmarking case studies. Section 5 shows the conclusion and future work.

\section{PROBLEM STATEMENT}

The HSF problem is considered as NP-hard even though it is composed of two stages with one processor at any of them. Vignier et al. (1999) [26] formed the problems according to shop classification $\alpha$, constraints and assumptions $\beta$, and the objective function considered $\gamma$. Each problem then is described with a triplet $\alpha / \beta / \gamma$. As for the proposed problem, the notation of the problem that will be solved can be performed by $\operatorname{HFS}\left(\left(R M^{k}\right)_{k=1}^{m}\right) \mid \operatorname{Prec}, \mathrm{M}_{\mathrm{j}}$, batch(b) $\mid \mathrm{C}_{\max }$.

This means that the system is a hybrid flow shop system with $\mathrm{k}$ stages and variable lot streaming (batch (b)). Each stage contains unrelated parallel eligible machines (Prec, $\mathrm{Mj}$ ) with the objective of minimization of the make-span Cmax as 
shown in Figure 1. The minimization of the make-span is often taken as a compromise between capacity-related and flow time-oriented objectives because of the assumption that it will also lead to short flow times. (Uetake et al., 1995) mentioned that make-span is a superior criterion to measure the overall manufacturing performance of HFS which includes different processes; however, it cannot always explain the adequately of the manufacturing performance under the operational conditions that require more capacity. The increase in capacity is done by an increasing number of products/ family of unit process time.

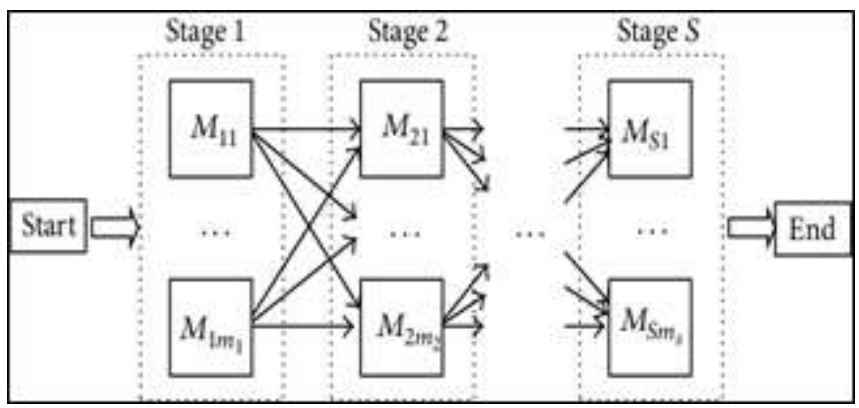

Figure 1: Eligible machines HFS system

As shown from the proposed problem, there are unrelated parallel machines that have variable speeds. The sublots size will be varied according to the machine`s speed as a higher machine`s speed will process a higher quantity of processed jobs.

In order to solve this problem, a mixed non-linear integer programming model is developed based on conjunctive constraints. The main faced problems are considered in three folds; the first one is to determine the sub-lots quantities for each machine, the second fold is to determine the sub-lot quantity for each machine for each job and the third fold is to schedule different sub-lots of jobs on the eligible unrelated parallel machines at each flow stages to minimize the makespan. The model is solved by lingo program version 18.0 that uses a branch and bound approach to get the optimum solution.

The following subsections show in detail the assumption of the mathematical model, the model indices, parameters and decision variables, and finally the mathematical model formulation.

\subsection{Assumptions}

The fundamental presumptions of this model can be condensed in the accompanying focuses:

Once a sub-lot of a job begins processing on its doled-out machine, no preemption is permitted.

The sub-lots can be split at each stage however it cannot be gathered once more.

A machine processes no more than one sub-lot at the same time.

Unexpected machine disappointments are dismissed, and no preventive maintenance activities are scheduled during processing the set of jobs $\mathrm{N}$.

\subsection{Indices}

$s t, k t$ : stage index where $s t$ and $k t \in\{1,2 \ldots, S T\}$.

$i m, r m$ : machine index where $i m$ and $r m \in\{1,2, \ldots . m s\}$. 
jo, lo: job index where $j o$ and $l o \in\{1,2, . . N\}$.

$b a, d a$ are sub-lot indices that $b a$, and $d a \in\{1,2, . . B\}$.

\subsection{Parameters}

$u u_{i m, j o, b a}$ : is the upper limit of the sub-lot $b a$ for the job jo on the machine im in $\mathrm{kg}$.

$l t_{i m, j o, b a}:$ is the lower limit of the sub-lot $b a$ for the job jo on the machine $i m$ in $\mathrm{kg}$.

$Q a_{s t, j o}:$ is the quantity of job jo on stage st in $\mathrm{kg}$.

$s e_{i m, j o}$ : is the machine speed when the machine $i m$ is processing job $j o$ in $\mathrm{kg} / \mathrm{min}$.

$s p_{i m, j o}$ : is the independent setup time of job jo on machine $\mathrm{im}$ in min.

$f_{i m, j o}$ : Binary number that deals with machine eligibility as it takes 1 if the job jo will be processed on the machine $i m$ or 0 otherwise.

\subsection{Decision variables}

Cmax : Make-span time.

$l o_{s t, i m, j o, b a}$ : Sub-Lot quantity of job jo that will be processed on the machine $i m$ located at stage $s t$.

$p o_{s t, i m, j o, b a}$ : Sub-Lot process time of job jo that will be processed on the machine im located at stage $s t$.

$o_{s t, i m, j o, b a}$ : Binary variable that indicates if sub-lot $b a$ of job $j o$ will be processed on the machine im it will take 1 or 0 otherwise.

$s r_{s t, i m, j o, b a}:$ Start time of sub-lot $b a$ of job jo on the machine $i m$ at stage $s t$.

$C o_{s t, i m, j o, b a}$ : Completion time of sub-lot $b a$ of job jo on the machine $i m$ at stage $s t$.

$d_{s t, i m, j o, l o}$ a binary variable that ensures job $l o$ is following job jo that it will take 1 if job lo follows job $j o$ and 0 otherwise

\subsection{Mathematical Model formulation}

$\min w=C \max$

$l o_{s t, i m, j o, b a} \leq u u_{i m, j o, b a} * o_{s t, i m, j o, b a} \forall i m, j o$, and $b a$

$l o_{s t, i m, j o, b a} \geq l t_{i m, j o, b a} * o_{s t, i m, j o, b a} \forall i m, j o$, and $b a$

$\sum_{b a j=1}^{B a j} \sum_{i m s=1}^{m s} l o_{s t, i m, j o, b a}=Q a_{s t, j o} \forall s t$ and $j o$

$p o_{s t, i m, j o, b a}=\left(\frac{l_{s t, i m, j o, b a}}{s e_{i m, j o}}+s p_{i m, j o}\right) \forall i m, j o$ and $b a=1$

$p o_{s t, i m, j o, b a}=\frac{l o_{s t, i m, j o, b a}}{s e_{i m, j o}} \forall i m, j o$, and $b a>1$

$o_{s t, i m, j o, b a} \leq f_{i m, j o} \forall s t, i m, j o$, and $b a$

$C o_{s t, i m, j o, b a} \geq\left(s r_{s t, i m, j o, b a}+p o_{s t, i m, j o, b a}\right) \forall s t, i m, j o$ and $b a=1$ 
$C o_{s t, i m, j o, b a} \geq\left(s r_{s t, i m, j o, b a}+p o_{s t, i m, j o, b a}\right) * o_{s t, i m, j o, b a} \forall s t, i m, j o$ and $b a>1$

$s r_{s t, i m, j o, d a} \geq C o_{s t, i m, j o, b a} \forall i m, j o, b a$ and $d$ while $b \neq d$

$s r_{s t, i m, j o, d a} \geq C o_{s t, i m, j o, b a} * d_{s t, i m, j o, l o} \forall s t, i m, j o, l o, b a$, and $d a$ while jo $\neq$ lo and $b a \neq d$

$d_{s t, i m, j o, l o}+d_{s t, i m, l o, j o}=1 \forall s t, i m, j o$, and lo while $j o \neq l o$

$\mathrm{sr}_{\mathrm{kt}, \mathrm{im}, \mathrm{jo}, \mathrm{da}} \leq \mathrm{Co}_{\mathrm{st}, \mathrm{im}, \mathrm{jo}, \mathrm{ba}} \forall \mathrm{st}, \mathrm{kt}, \mathrm{im}, \mathrm{rm}$, jo, ba, and da while st $\neq \mathrm{kt}$, im $\neq \mathrm{rm}$ and ba $\neq \mathrm{da} \quad(13)$

$C \max \geq C_{S t, i m, j o, b a} \forall s t, i m, j o$ and $b$

$o_{s t, i m, j o, b a} \in\{0,1\} \forall s t, i m, j o$, and $b a$

$d_{s t, i m, j o, l o} \in\{0,1\} \forall$ st, im, jo and lo

In the above formulation, the objective function of the model which is designed to minimize the total makespan, Cmax is shown at Eq. (1). Eqs. from (2-16) represent the model constraints. Eqs. (2-3) represent the upper and lower limits for sub-lot ba per each job jo on machine $\mathrm{im}_{s}$. Eq. (4) shows that the sum of the quantities of the sub-lot ba for the job jo must not exceed the total demand for the jobjo. Eq. (5) calculates the processing time for the first sub-lot $b a$ per each job jo on machine $\mathrm{im}_{s}$. Eq. (6) calculates the processing time for the sub-lots after the first sub-lot ba per each job jo on machine $i m_{s}$. Eq. (7) ensures that the binary variable $o_{s t, i m, j o, b a}$ does not exceed the eligibility number $f_{i m, j o}$. Eq. (8) ensures that the completion time for the first sub-lot $b a$ does not exceed the sum of both the processing time and start time. Eq. (9) ensures that the completion time for each sub-lot ba does not exceed the sum of both the processing time and start time. Eq. (10) ensures that the sub-lot $d a$ must begin its processing after the sub-lot ba is processed on the machine $i_{s}$. Eq. (11) ensures that the sub-lots of job lo must begin their processing after the sub-lots of job jo are processed on a machine $i m_{s}$. Eq. (12) ensures that there are no two different jobs on the same machine at the same time. Eq. (13) ensures that the processes on the next stage do not begin without the processes of the last stages are finished. Eq. (14) calculates the make-span that is equal to the completion time of the last item for sub-lot $b a$ in the final stage. Eq. (15) is a binary variable that takes 1 if the sub-lot will be processed on the machine and 0 otherwise. Eq. (16) is a binary variable that takes 1 if the job 1 is processed after job $\mathrm{j}$ and 0 otherwise.

\section{REAL CASE APPLICATION}

United Ltd. Co. is an Egyptian company for producing metal nails. This company is exporting its products for some countries like the USA, and some of the Arabian countries. The nails have variations in their characteristics according to the customers' requirements. The characteristics of nails are varied with respect to their diameter, length, endpoint and the type of collecting of nails. The diameter is varied from 2.1-3.2 mm. The length is varied from $45-85 \mathrm{~cm}$. The endpoint has six types; BBS, BCS, BDS, BLS, BDR or BDS; and the nails collection that can be collected by cupper coil or plastic strip. The raw material of the company is a steel wire with a diameter of $6 \mathrm{~mm}$. The production of this company is about 100 tons/ month.

\section{Table 1: Product specification and quantities}

\begin{tabular}{|c|l|l|l|l|l|}
\hline Stage & Machine & Job1 & Job2 & Job3 & Job4 \\
\hline \multirow{2}{*}{ Drawing } & M1 & 1 & 0 & 0 & 0 \\
\cline { 2 - 6 } & M2 & 0 & 1 & 1 & 1 \\
\hline
\end{tabular}




\begin{tabular}{|c|c|c|c|c|c|}
\hline \multirow[t]{13}{*}{ Nailing } & M3 & 1 & 1 & 1 & 1 \\
\hline & M4 & 1 & 1 & 1 & 1 \\
\hline & M5 & 1 & 1 & 1 & 1 \\
\hline & M6 & 1 & 1 & 1 & 1 \\
\hline & M7 & 1 & 1 & 1 & 1 \\
\hline & M8 & 1 & 1 & 1 & 1 \\
\hline & M9 & 1 & 1 & 1 & 1 \\
\hline & M10 & 0 & 1 & 1 & 1 \\
\hline & M11 & 0 & 1 & 1 & 1 \\
\hline & M12 & 0 & 1 & 1 & 1 \\
\hline & M13 & 0 & 1 & 1 & 1 \\
\hline & M14 & 0 & 1 & 1 & 1 \\
\hline & M15 & 0 & 1 & 1 & 1 \\
\hline \multirow[t]{2}{*}{ Cleaning } & M16 & 1 & 1 & 1 & 1 \\
\hline & M17 & 1 & 1 & 1 & 1 \\
\hline \multirow[t]{5}{*}{ Screwing } & M18 & 1 & 1 & 1 & 1 \\
\hline & M19 & 1 & 1 & 1 & 1 \\
\hline & M20 & 1 & 1 & 1 & 1 \\
\hline & M21 & 1 & 1 & 1 & 1 \\
\hline & M22 & 1 & 1 & 1 & 1 \\
\hline \multirow[t]{5}{*}{ Coil } & M23 & 1 & 1 & 1 & 1 \\
\hline & M24 & 1 & 1 & 1 & 1 \\
\hline & M25 & 1 & 1 & 1 & 1 \\
\hline & M26 & 1 & 1 & 1 & 1 \\
\hline & M27 & 1 & 1 & 1 & 1 \\
\hline
\end{tabular}

The workshop of the company consists of 6 stages. The first one is the drawing stage. This stage consists of 4 lines; line 1 can reduce the wire up to $2.5 \mathrm{~mm}$, and the remaining three lines for $\leq 2.5 \mathrm{~mm}$. The second stage is the nailing stage that has 50 parallel unrelated eligible machines. Twenty-two machines can produce nails from 2.8 to 3.2 in diameter. Twenty-eight eligible machines can produce nails from 2.5 to 3.2 diameter. The third stage is cleaning the nails from grass and swarf that consists of eight machines. They have the same duration time for all containers. The fourth stage is the screwing stage that contains 14 machines used to make scratches for the nails. This stage consists of two types of machines, 6 for screwing and 8 for straight scratches. The fifth stage is the collection stage. There are two ways for copper coiling; Copper coil that can be produced by ten machines and plastic strip that can be produced by three machines. The final stage is a manual package by eight persons. To fulfil the customers' requirements the company has two shifts 10 working hours per shift and two hours overtime at the first shift. Figure 2 shows the workshop arrangement. The main problems of the company are to determine the optimum sub-lot quantity with respect to the pre-determined volume of containers, the number of sub-lots per each job and to schedule the different sub-lot to each machine among the stages to minimize the total make-span of the system and thus achieve customers' satisfaction.

A sample case is solved by the proposed model shown in Section 2 to get the minimum make-span. Four jobs are selected that its quantity in tons and specification are shown in Table1. Tables 2, 3, 4 show the machines ', eligibility, speed and setup time.

Table 2: Machine eligibility

\begin{tabular}{|l|c|c|r|r|}
\hline $\begin{array}{l}\text { Job } \\
\text { No. }\end{array}$ & $\begin{array}{c}\text { Diameter } \\
(\mathbf{m m})\end{array}$ & $\begin{array}{c}\text { Length } \\
(\mathbf{m m})\end{array}$ & Endpoint & $\begin{array}{c}\text { Quantity } \\
\text { (in tons) }\end{array}$ \\
\hline Job 1 & 2.3 & 45 & BBS & 2 \\
\hline
\end{tabular}




\begin{tabular}{|l|l|l|l|l|}
\hline Job 2 & 2.5 & 45 & BBD & 3 \\
\hline Job 3 & 2.5 & 50 & BBL & 4 \\
\hline Job 4 & 2.5 & 55 & BBS & 5 \\
\hline
\end{tabular}

Table 3: Machines speed in ton/hrs

\begin{tabular}{|c|c|c|c|c|c|}
\hline Stage & Machine & Job1 & Job2 & Job3 & Job4 \\
\hline \multirow{2}{*}{ Drawing } & M1 & 0.2 & -1 & -1 & -1 \\
\hline & M2 & -1 & 0.6 & 0.6 & 0.6 \\
\hline \multirow{13}{*}{ Nailing } & M3 & 0.02 & 0.03 & 0.04 & 0.04 \\
\hline & M4 & 0.02 & 0.03 & 0.04 & 0.04 \\
\hline & M5 & 0.02 & 0.03 & 0.04 & 0.04 \\
\hline & M6 & 0.02 & 0.03 & 0.04 & 0.04 \\
\hline & M7 & 0.02 & 0.03 & 0.03 & 0.04 \\
\hline & M8 & 0.02 & 0.03 & 0.03 & 0.04 \\
\hline & M9 & 0.02 & 0.03 & 0.03 & 0.04 \\
\hline & M10 & -1 & 0.05 & 0.06 & 0.07 \\
\hline & M11 & -1 & 0.05 & 0.06 & 0.07 \\
\hline & M12 & -1 & 0.05 & 0.06 & 0.07 \\
\hline & M13 & -1 & 0.05 & 0.06 & 0.07 \\
\hline & M14 & -1 & 0.05 & 0.06 & 0.07 \\
\hline & M15 & -1 & 0.05 & 0.06 & 0.07 \\
\hline \multirow{2}{*}{ Cleaning } & M16 & 0.37 & 0.37 & 0.37 & 0.37 \\
\hline & M17 & 0.37 & 0.37 & 0.37 & 0.37 \\
\hline \multirow{5}{*}{ Screwing } & M18 & 0.07 & 0.08 & 0.09 & 0.09 \\
\hline & M19 & 0.07 & 0.08 & 0.09 & 0.09 \\
\hline & M20 & 0.07 & 0.08 & 0.09 & 0.09 \\
\hline & M21 & 0.07 & 0.08 & 0.09 & 0.09 \\
\hline & M22 & 0.07 & 0.08 & 0.09 & 0.09 \\
\hline \multirow{5}{*}{ Coil } & M23 & 0.01 & 0.008 & 0.01 & 0.01 \\
\hline & M24 & 0.01 & 0.008 & 0.01 & 0.01 \\
\hline & M25 & 0.01 & 0.008 & 0.01 & 0.01 \\
\hline & M26 & 0.01 & 0.008 & 0.01 & 0.01 \\
\hline & M27 & 0.01 & 0.008 & 0.01 & 0.01 \\
\hline
\end{tabular}

Table 4: Machines setup times in hrs

\begin{tabular}{|l|l|l|l|l|l|}
\hline Stage & Machine & Job1 & Job2 & Job3 & Job4 \\
\hline \multirow{4}{*}{ Drawing } & M1 & 0.5 & 0 & 0 & 0 \\
\cline { 2 - 6 } & M2 & 0 & 0.5 & 0.5 & 0.5 \\
\hline \multirow{5}{*}{ Nailing } & M3 & 0.15 & 0.15 & 0.15 & 0.15 \\
\cline { 2 - 6 } & M4 & 0.15 & 0.15 & 0.15 & 0.15 \\
\cline { 2 - 6 } & M5 & 0.15 & 0.15 & 0.15 & 0.15 \\
\cline { 2 - 6 } & M6 & 0.15 & 0.15 & 0.15 & 0.15 \\
\cline { 2 - 6 } & M7 & 0.15 & 0.15 & 0.15 & 0.15 \\
\cline { 2 - 6 } & M8 & 0.15 & 0.15 & 0.15 & 0.15 \\
\cline { 2 - 6 } & M9 & 0.15 & 0.15 & 0.15 & 0.15 \\
\cline { 2 - 6 } & M10 & 0 & 0.15 & 0.15 & 0.15 \\
\cline { 2 - 6 } & M11 & 0 & 0.15 & 0.15 & 0.15 \\
\cline { 2 - 6 } & M12 & 0 & 0.15 & 0.15 & 0.15 \\
\cline { 2 - 6 } & M13 & 0 & 0.15 & 0.15 & 0.15 \\
\cline { 2 - 6 } & M14 & 0 & 0.15 & 0.15 & 0.15 \\
\cline { 2 - 6 } & M15 & 0 & 0.15 & 0.15 & 0.15 \\
\hline \multirow{7}{*}{ Cleaning } & M16 & 0.15 & 0.15 & 0.15 & 0.15 \\
\cline { 2 - 6 } & M17 & 0.15 & 0.15 & 0.15 & 0.15 \\
\hline Screwing & M18 & 0.15 & 0.15 & 0.15 & 0.15 \\
\hline
\end{tabular}




\begin{tabular}{|l|l|l|l|l|l|}
\hline \multirow{5}{*}{} & M19 & 0.15 & 0.15 & 0.15 & 0.15 \\
\cline { 2 - 6 } & M20 & 0.15 & 0.15 & 0.15 & 0.15 \\
\cline { 2 - 6 } & M21 & 0.15 & 0.15 & 0.15 & 0.15 \\
\cline { 2 - 6 } & M22 & 0.15 & 0.15 & 0.15 & 0.15 \\
\hline \multirow{4}{*}{ Coil } & M23 & 0.3 & 0.3 & 0.3 & 0.3 \\
\cline { 2 - 6 } & M24 & 0.3 & 0.3 & 0.3 & 0.3 \\
\cline { 2 - 6 } & M25 & 0.3 & 0.3 & 0.3 & 0.3 \\
\cline { 2 - 6 } & M26 & 0.3 & 0.3 & 0.3 & 0.3 \\
\cline { 2 - 6 } & M27 & 0.3 & 0.3 & 0.3 & 0.3 \\
\hline
\end{tabular}

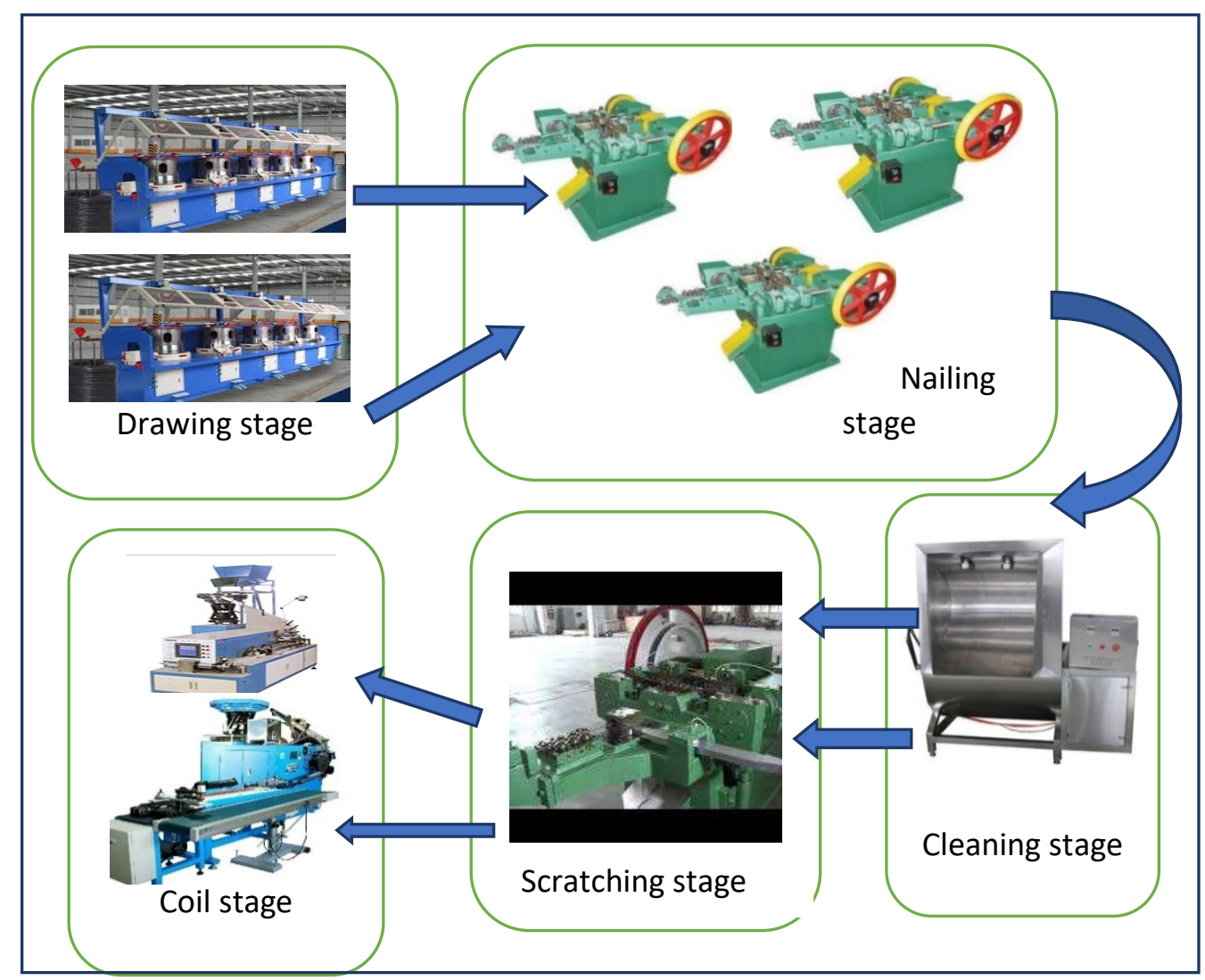

Figure 2: Workshop stages arrangements

It is worth saying that speed of (-1) in Table (3) is written to avoid getting unavailable solution as in the proposed model the machine speed is at the denominator in the equations 5 and 6.

The scheduling of the above case is usually made in a manual process. The production planning engineer follows the assumptions:

- The total quantity of the job is divided into sub-lots. The quantity of one sub-lot is equal to the maximum capacity of the available container. As for our case, the maximum container capacity is 0.9 ton. If we calculate the total sub-lots for job 1 as an example, it will be 2/0.9=2 sub-lots and the remaining 0.2 ton will be kept as a separate sub-lot in a third container.

- The production planning engineer also considers that he wants to reduce the total changeover. So he follows the group technology technique. This technique depends on the merging of similar jobs on the same machine. In our 
case, jobs 2, 3, 4 will be treated as one job at the first stage as they have the same diameter then it will be separated in the following stages.

- The production planning engineer also arranges the sub-lots based on the first empty machine in the same stage. In our case, considering stage 2 , if machine 3 is empty before machine 4 , then the sub-lot from machine 2 in stage 1 will be processed on machine 3 instead of machine 4 .

- Finally, the production planning engineer considers that there is no intersection between the sub-lots which means that if the sub-lot begins the process on the machine, it must finish its processing.

By applying our current model that this research is proposing on the case study data, the make-span was found to be equal to 332 hrs. Table 5 below shows the sub-lot arrangement on the machines while Figure 3 shows the percentage of machine utilization at each stage by using the Microsoft project management program. The production planning engineer emphasized that the make-span using his technique is 430 hrs which means that 98 hrs is saved by our current proposed model.

So, the improvement can be calculated by

Cmax Imp. $=\left|\frac{\mathrm{C}_{\max } \text { by prop.model } \quad \text { max by act. }}{\mathrm{C}_{\max } \text { by prop.model }}\right| * 100$

$$
\text { Cmax Improvement }=\left|\frac{332-430}{332}\right| * 100=29.52 \%
$$

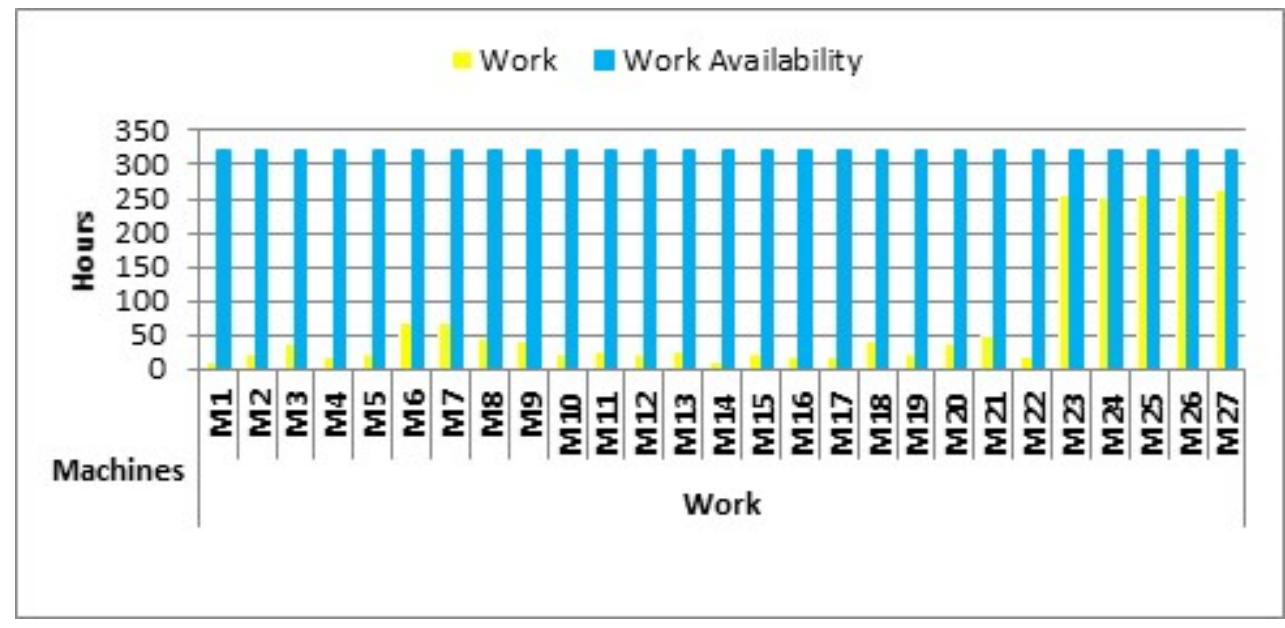

Figure 3: Total working hours for each machine

Figure (3) shows that the availability of the machine compared to the working hours for each machine. As for stages $1,2,3$, and 4 , we can notice that there is a lot of remaining available time while stage 5 can be a bottleneck for the workshop. From the Figure we can calculate the utilization for each machine, utilization that is calculated by the following formula:

$$
\mu=(\text { working hours }) /(\text { available hours })(18)
$$

Average workshop utiliztion $=\sum_{i=1}^{M}$ Machine Utilization $/ n$ (19) 


$$
\begin{gathered}
\text { Average workshop utiliztion for proposed model }=\frac{584.8}{27}=21.66 \\
\text { Average workshop utiliztion for actual scheduling }=\frac{646.08}{27}=23.93
\end{gathered}
$$

From the above results, the average utilization for the workshop is from the proposed model is convergent to the average utilization for the actual scheduling.

Table (5) shows the utilization factor percentage for each machine that indicates there are the highest utilization for machine 27 and the lowest utilization for machine 1. The Table also indicates that the utilization of stage 5 is the highest utilization and the lowest utilization is at stage 1 .

Table 5: Machine utilization for each machine

\begin{tabular}{|l|l|l|l|l|l|l|l|l|l|l|l|l|l|l|l|l|l|l|l|l|l|l|l|l|l|l|l|}
\hline M/C & M1 & M2 & M3 & M4 & M5 & M6 & M7 & M8 & M9 & M10 & M11 & M12 & M13 & M14 & M15 & M16 & M17 & M18 & M19 & M20 & M21 & M22 & M23 & M24 & M25 & M26 & M27 \\
\hline$\mu$ & 2.84 & 6.60 & 11.30 & 5.55 & 6.36 & 20.43 & 20.25 & 13.58 & 12.22 & 6.45 & 7.35 & 6.45 & 7.08 & 2.89 & 6.41 & 5.86 & 5.66 & 12.76 & 5.94 & 10.94 & 14.95 & 5.32 & 76.64 & 75.70 & 77.44 & 77.62 & 79.88 \\
\hline
\end{tabular}

\section{COMPARATIVE STUDY}

In this section, a comparative study will be performed between 4 benchmarking case studies from the literature and our proposed model. The proposed model will be compared with each one discretely of mentioned case studies for comparison. Lingo solver version 11.0 on the laptop with processor $2.5 \mathrm{GHz}$ and ram $4 \mathrm{~GB}$ is used to solve the model with the same data of each one. The case studies have been solved by many heuristics and methods so the comparison will be between the results of the proposed model and other heuristics and methods. The case studies share the following characteristics:

All of them have no eligible machines.

The processing time includes setup time.

The authors of the research papers that present case studies (1), (3), and (4) assumed the quantity equal to 1, this paper followed this argument to compare the effect of batching on these cases and assumed that it is equal to $1 \mathrm{~kg}$ so the sub-lot will be in gm.

\subsection{Case study (1)}

This paper (Li et al., 2014) [14] presented solving hybrid flow-shop by using a hybrid variable neighbourhood search (HVNS) algorithm that combines the chemical-reaction optimization (CRO) and the Estimation of Distribution (EDA). A dynamic neighbourhood set update mechanism is utilized to exploit the potential search space. The researchers of this case used eight neighbourhood structures as follows: swap two positions structure; insertion structure; reverse the elements between two positions structure; swap elements structure; swap the elements with the first and the last element structure; insert elements before the first and after the last structure; swap elements at one-point structure; and insert at one-point structure. To examine the effectiveness of their algorithm, they compared the proposed algorithm with particle swarm methodology, lower bound, branch and bound approach, artificial immune system, and ant colony optimization algorithms. Their study concluded that their proposed algorithm is more efficient than all of them generally. Our proposed model was applied in this case study with the number of sub-lots 3, an upper limit and lower bounds are 1 and 0 representatively on the problem. This problem consists of 5 stages that contain 15 machines as 3 machines for each one and will process 15 jobs. Table (6) shows the process data of the problem. When solving the problem with our model the make-span is 68 min 
while the make-span with HVNS solving is 79 that is meaning there is reduce in make-span with 11 min. In Figure (4) there is a comparison between the mentioned algorithms and our model for same example. This Figure shows that our model is better than all the other algorithms except the lower bound as it was. However, the lower bound is very timeconsuming compared with other algorithms (Li et al., 2014).

Table 6: Processing Data for Case Study (1)

\begin{tabular}{|c|c|c|c|c|c|c|c|c|c|c|c|c|c|c|c|}
\hline $\mathbf{M} / \mathbf{C}$ & J1 & J2 & J3 & J4 & J5 & J6 & J7 & J8 & J9 & J10 & J11 & J12 & J13 & J14 & $\mathbf{J 1 5}$ \\
\hline M1 & 8 & 14 & 7 & 15 & 7 & 5 & 9 & 14 & 7 & 15 & 10 & 5 & 6 & 14 & 5 \\
\hline M2 & 8 & 14 & 7 & 15 & 7 & 5 & 9 & 14 & 7 & 15 & 10 & 5 & 6 & 14 & 5 \\
\hline M3 & 8 & 14 & 7 & 15 & 7 & 5 & 9 & 14 & 7 & 15 & 10 & 5 & 6 & 14 & 5 \\
\hline M4 & 4 & 4 & 10 & 3 & 9 & 16 & 14 & 11 & 7 & 10 & 3 & 10 & 4 & 10 & 8 \\
\hline M5 & 4 & 4 & 10 & 3 & 9 & 16 & 14 & 11 & 7 & 10 & 3 & 10 & 4 & 10 & 8 \\
\hline M6 & 4 & 4 & 10 & 3 & 9 & 16 & 14 & 11 & 7 & 10 & 3 & 10 & 4 & 10 & 8 \\
\hline M7 & 9 & 4 & 5 & 13 & 4 & 10 & 16 & 10 & 9 & 6 & 10 & 2 & 8 & 12 & 15 \\
\hline M8 & 9 & 4 & 5 & 13 & 4 & 10 & 16 & 10 & 9 & 6 & 10 & 2 & 8 & 12 & 15 \\
\hline M9 & 9 & 4 & 5 & 13 & 4 & 10 & 16 & 10 & 9 & 6 & 10 & 2 & 8 & 12 & 15 \\
\hline M10 & 10 & 14 & 3 & 4 & 14 & 10 & 15 & 13 & 5 & 6 & 8 & 5 & 13 & 8 & 13 \\
\hline M11 & 10 & 14 & 3 & 4 & 14 & 10 & 15 & 13 & 5 & 6 & 8 & 5 & 13 & 8 & 13 \\
\hline M12 & 10 & 14 & 3 & 4 & 14 & 10 & 15 & 13 & 5 & 6 & 8 & 5 & 13 & 8 & 13 \\
\hline M13 & 4 & 3 & 14 & 7 & 15 & 15 & 14 & 13 & 10 & 7 & 3 & 5 & 8 & 9 & 14 \\
\hline M14 & 4 & 3 & 14 & 7 & 15 & 15 & 14 & 13 & 10 & 7 & 3 & 5 & 8 & 9 & 14 \\
\hline M15 & 4 & 3 & 14 & 7 & 15 & 15 & 14 & 13 & 10 & 7 & 3 & 5 & 8 & 9 & 14 \\
\hline
\end{tabular}




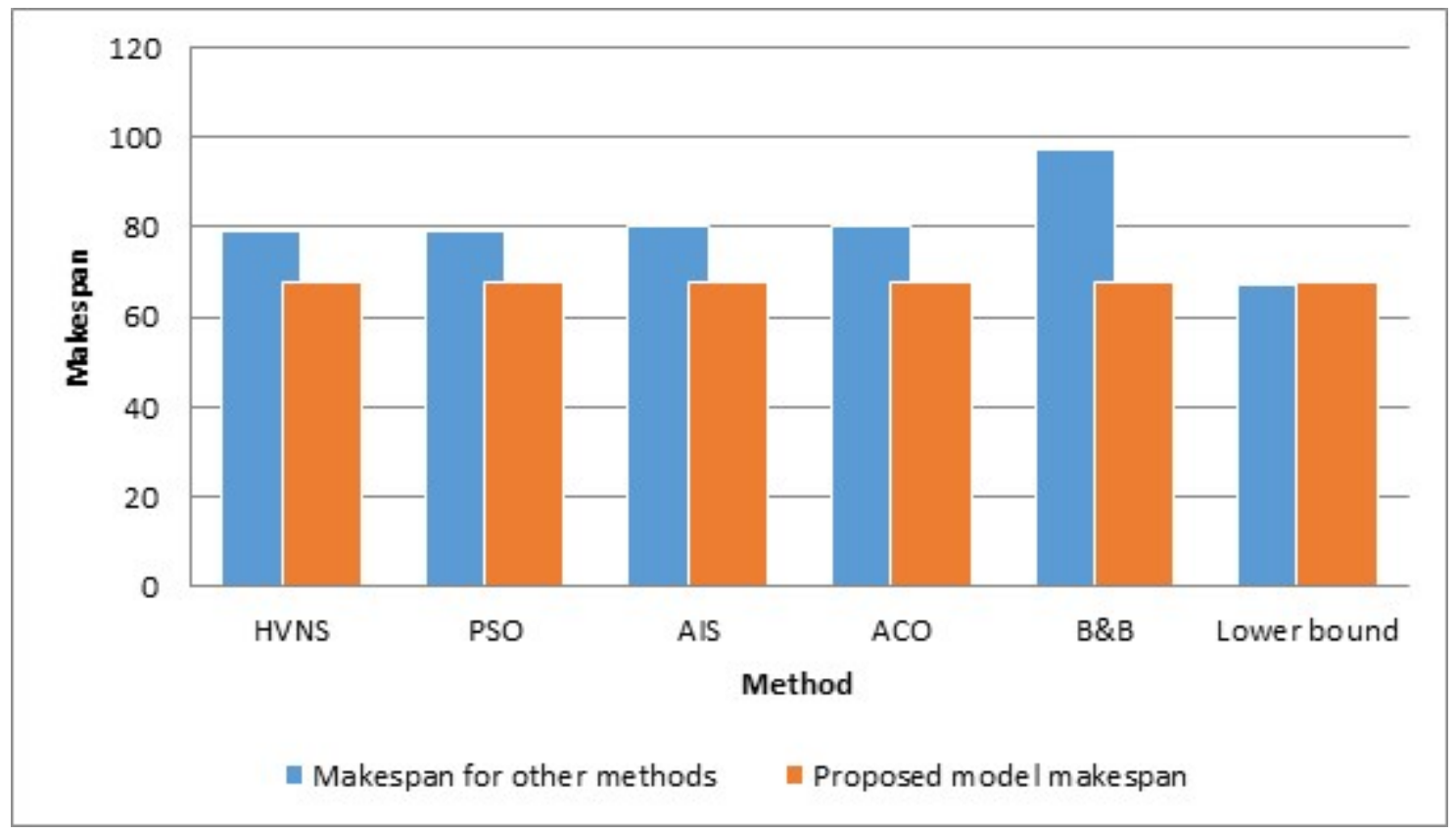

Figure 4: Comparison make-span between different methods and proposed model for case1

\subsection{Case study (2)}

This paper (B. Zhang et al., 2017) [27]studied a hybrid flow shop with a fixed number of sub-lot for each job. The researchers handled the problem by using the shortest waiting time. They used two competitive methods. The first method is called "Solution Dependent Rule", referred to as SDR which is widely used to arrange these concurrently arriving jobs according to their occurrence order in the solution representation. The other method is called "Random Rule", referred to as RR which schedules the concurrently arriving jobs in a random manner. Table (7) below shows the data for the numerical example used in their paper. The quantity of each job is represented by the fixed number of sub-lots. The makespan for the two

Table7: The Data For the Numerical Example for case 2

\begin{tabular}{|l|l|l|l|l|}
\hline \multirow{2}{*}{$\begin{array}{l}\text { Job (number of } \\
\text { sub-lots) }\end{array}$} & \multicolumn{2}{|l|}{ Stage 1 } & \multicolumn{2}{l|}{ Stage 2 } \\
\cline { 2 - 5 } Job1 (3) & 6 & 6 & 2 & 2 \\
\hline Job2 (2) & 4 & 4 & 3 & 3 \\
\hline Job3 (1) & 2 & 2 & 3 & 3 \\
\hline Job4 (2) & 2 & 2 & 4 & 4 \\
\hline
\end{tabular}

When solving this example by our proposed model with a number of sub-lots equal to 3, the upper and lower bounds are 3 and 1 representatively the make-span was 19 min. Figure (5) shows the Gantt chart for our model solution, while Figure (6) shows the sub-lots quantity for each machine. The make-span is lower than the two approaches by $5 \mathrm{~min}$ and there was no gap between the processed sub-lots as shown in Figure (7) used methods was 24 min for each one. Table (3) below shows the details for the numerical example used in their paper. The amount of each product is considered by fixed number of sub-lots. The make-span for the two used approaches was $24 \mathrm{~min}$ for each one.

\begin{tabular}{|l|l|l|l|}
\hline S2 & M4 & $\mathrm{Sb}(2,4,1,3)=3$ \\
\hline
\end{tabular}




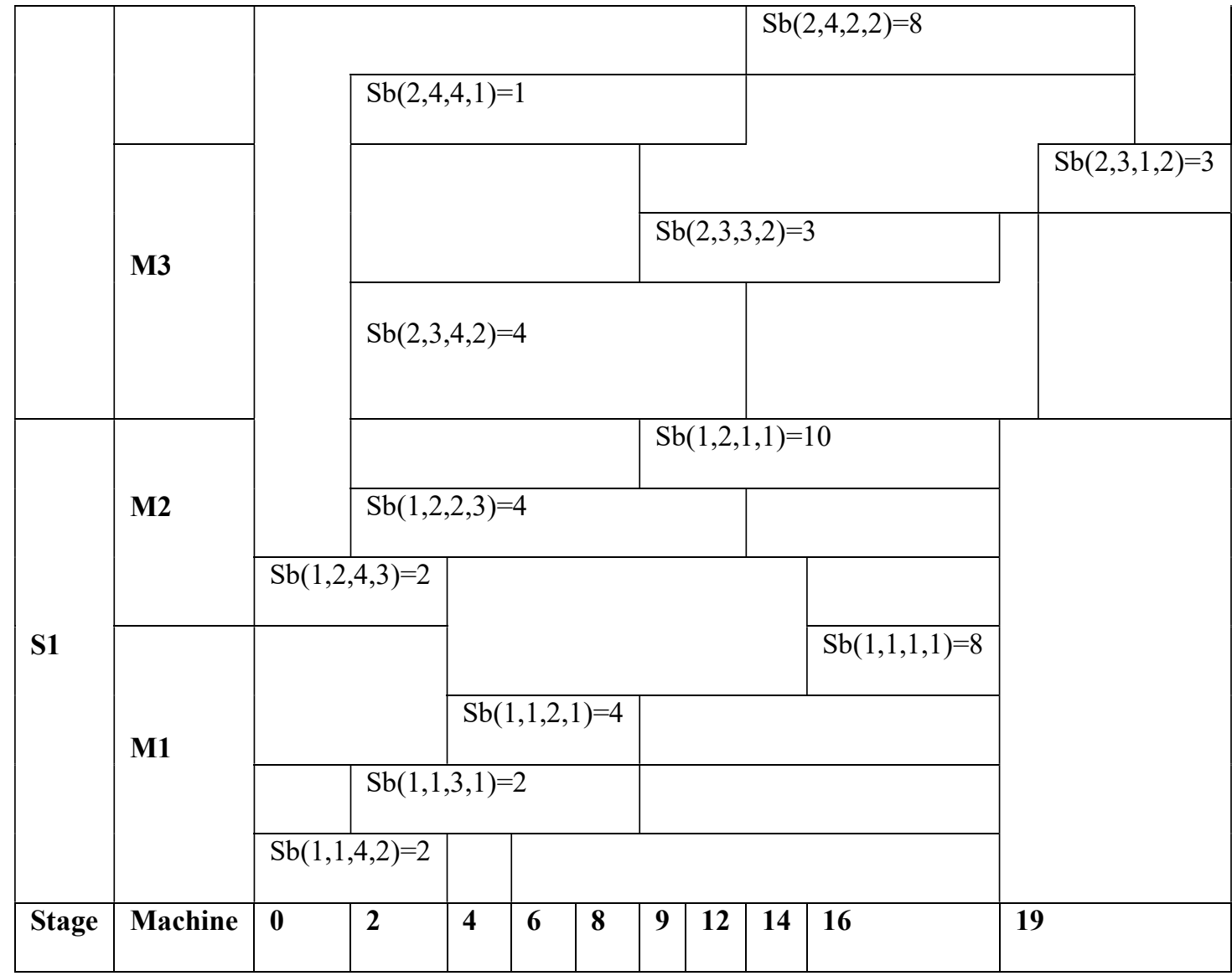

Figure 5: Gantt chart for a representative solution with $b=3, U L=3$, and $L L=1$ for case 2

\begin{tabular}{|c|c|c|}
\hline \multirow{6}{*}{$\mathbf{S 2}$} & \multirow{3}{*}{ M4 } & $\mathrm{Sb}(2,4,1,3)=1.5$ \\
\hline & & $\mathrm{Sb}(2,4,2,2)=2$ \\
\hline & & $\mathrm{Sb}(2,4,4,1)=1$ \\
\hline & \multirow{3}{*}{ M3 } & $\mathrm{Sb}(2,3,1,2)=1.5$ \\
\hline & & $\mathrm{Sb}(2,3,3,2)=1$ \\
\hline & & $\mathrm{Sb}(2,3,4,2)=1$ \\
\hline \multirow{7}{*}{ S1 } & \multirow{3}{*}{ M2 } & $\mathrm{Sb}(1,2,1,1)=1.67$ \\
\hline & & $\mathrm{Sb}(1,2,2,3)=1$ \\
\hline & & $\mathrm{Sb}(1,2,4,3)=1$ \\
\hline & \multirow{4}{*}{ M1 } & $\mathrm{Sb}(1,1,1,1)=1.33$ \\
\hline & & $\mathrm{Sb}(1,1,2,1)=1$ \\
\hline & & $\mathrm{Sb}(1,1,3,1)=1$ \\
\hline & & $\mathrm{Sb}(1,1,4,2)=1$ \\
\hline
\end{tabular}




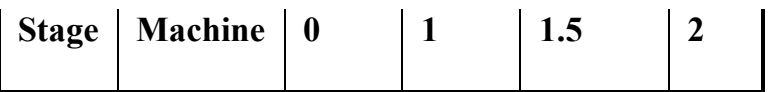

Figure 6: Sub-lots quantity for a representative solution with $b=3, U L=3$, and $L L=1$ for case 2

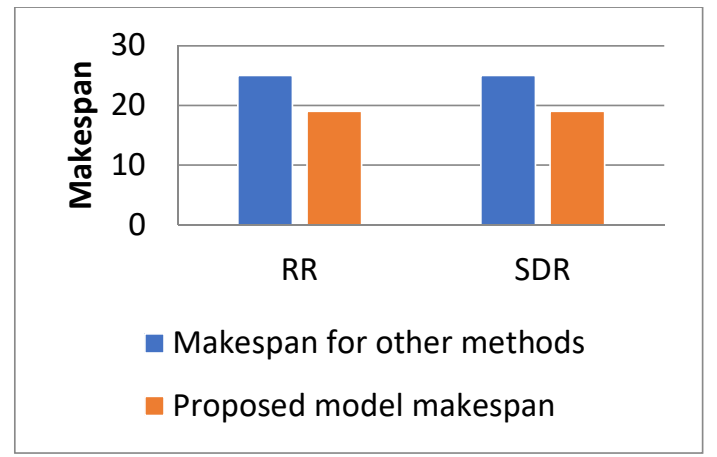

Figure 7: Makespan comparison for case study 2

\subsection{Case study (3)}

[28], used the differential evolution method with a local search to solve the problem (Data shown in Table (8) below). Their research argued that this method is more effective than the genetic algorithm. They compared the make-span (for the mentioned problem) that was solved by both the differential evolution method and the genetic algorithm in research (Cui et al., 2005). The differential evolution make-span was 299 while the make-span for the genetic algorithm was 347 min. When solving this case by our proposed model with a number of sub-lots equal to 3 , upper and lower bounds are 1 and 0 representatively. The make-span is $235.41 \mathrm{~min}$. This means that there is a reduction in make-span by 112 min for genetic algorithm and 64 min for differential evolution method as shown in Figure (8) below.

Table 8: The processing time for problem Case Study 3

\begin{tabular}{|c|c|c|c|c|c|c|c|c|c|c|}
\hline \multirow{3}{*}{$\begin{array}{c}\text { Stag } \\
\text { e } \\
\text { Jobs }\end{array}$} & \multicolumn{3}{|c|}{1} & \multicolumn{2}{|c|}{2} & \multicolumn{2}{|c|}{3} & \multicolumn{3}{|c|}{4} \\
\hline & \multicolumn{10}{|c|}{ Machines } \\
\hline & 1 & 2 & 3 & 4 & 5 & 6 & 7 & 8 & 9 & 10 \\
\hline 1 & 45 & 48 & 50 & 35 & 35 & 30 & 30 & 35 & 25 & 26 \\
\hline 2 & 45 & 50 & 45 & 35 & 36 & 35 & 35 & 34 & 25 & 30 \\
\hline 3 & 50 & 45 & 46 & 35 & 36 & 36 & 31 & 34 & 30 & 31 \\
\hline 4 & 50 & 48 & 48 & 34 & 38 & 35 & 32 & 33 & 37 & 31 \\
\hline 5 & 45 & 46 & 48 & 30 & 35 & 50 & 34 & 32 & 38 & 31 \\
\hline 6 & 45 & 45 & 45 & 30 & 35 & 50 & 33 & 32 & 30 & 26 \\
\hline 7 & 47 & 50 & 47 & 31 & 30 & 35 & 35 & 31 & 39 & 25 \\
\hline 8 & 50 & 45 & 48 & 32 & 30 & 34 & 34 & 30 & 34 & 27 \\
\hline 9 & 48 & 46 & 46 & 33 & 34 & 30 & 34 & 30 & 35 & 25 \\
\hline
\end{tabular}




\begin{tabular}{|l|l|l|l|l|l|l|l|l|l|l|}
\hline 10 & 45 & 47 & 47 & 33 & 33 & 30 & 35 & 34 & 32 & 26 \\
\hline 11 & 46 & 50 & 45 & 34 & 30 & 50 & 30 & 35 & 31 & 25 \\
\hline 12 & 48 & 50 & 47 & 35 & 31 & 35 & 32 & 30 & 25 & 30 \\
\hline
\end{tabular}

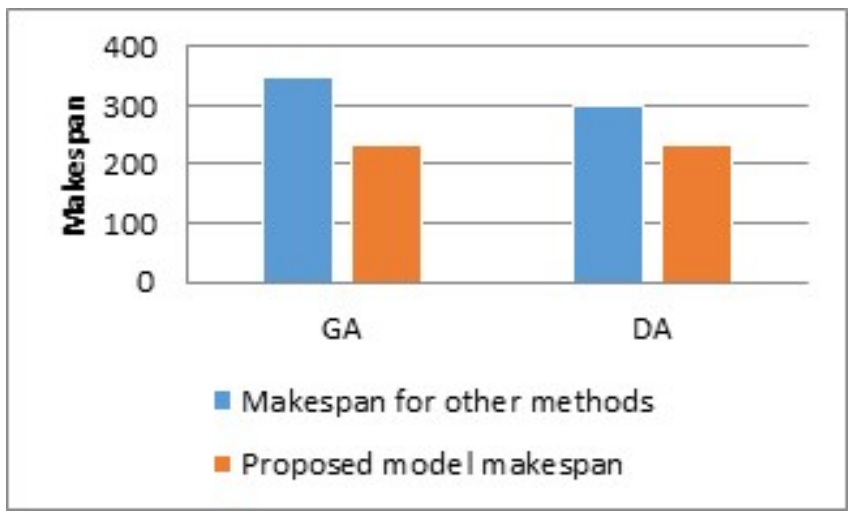

Figure 7: Comparison between differential evolution, genetic algorithm, and the proposed model for Case Study 3

\subsection{Case study (4)}

As for this paper [29], the researchers used a genetic algorithm with a scatter search to solve a hybrid flow shop with missing operations problem. They made 20 runs with different sequences for jobs and got the make-span. Table (9) shows the data. When solving this example by our model with a maximum number of sub-lots equal to 3 , the upper and lower bounds are 1 and 0 representatively. The make-span is 43 Seconds with the sequence shown in Table (10) below. Figure (9) shows the comparison between all the mentioned sequences and our proposed model.

Table 9: The Processing Time (sec) for Example of Case Study (4)

\begin{tabular}{|l|l|l|l|l|l|}
\hline \multirow{2}{*}{ Stage } & \multicolumn{5}{l}{ Jobs } \\
\cline { 2 - 6 } & $\mathbf{1}$ & $\mathbf{2}$ & $\mathbf{3}$ & $\mathbf{4}$ & $\mathbf{5}$ \\
\hline $\mathbf{1}$ & 2 & 4 & 4 & 2 & 2 \\
\hline $\mathbf{2}$ & 14 & 6 & 10 & 2 & 2 \\
\hline $\mathbf{3}$ & 10 & 10 & 4 & 8 & 8 \\
\hline
\end{tabular}

Table 10: The job Sequences for The Example of Case Study (4) for Proposed Model

\begin{tabular}{|l|l|l|l|l|}
\hline Stage & $\mathbf{1}$ & \multicolumn{2}{l|}{$\mathbf{2}$} & $\mathbf{3}$ \\
\hline Machine & $\mathbf{1}$ & $\mathbf{2}$ & $\mathbf{3}$ & $\mathbf{4}$ \\
\hline Sequence(job,Sublot) & 5,1 & 5,1 & 5,3 & 5,3 \\
\cline { 2 - 5 } & 4,1 & 5,2 & 3,1 & 4,2 \\
\hline
\end{tabular}




\begin{tabular}{|l|l|l|l|l|}
\hline \multirow{2}{*}{} & 2,2 & 3,1 & 1,2 & 2,2 \\
\cline { 2 - 5 } & 1,1 & & & 1,1 \\
\hline
\end{tabular}

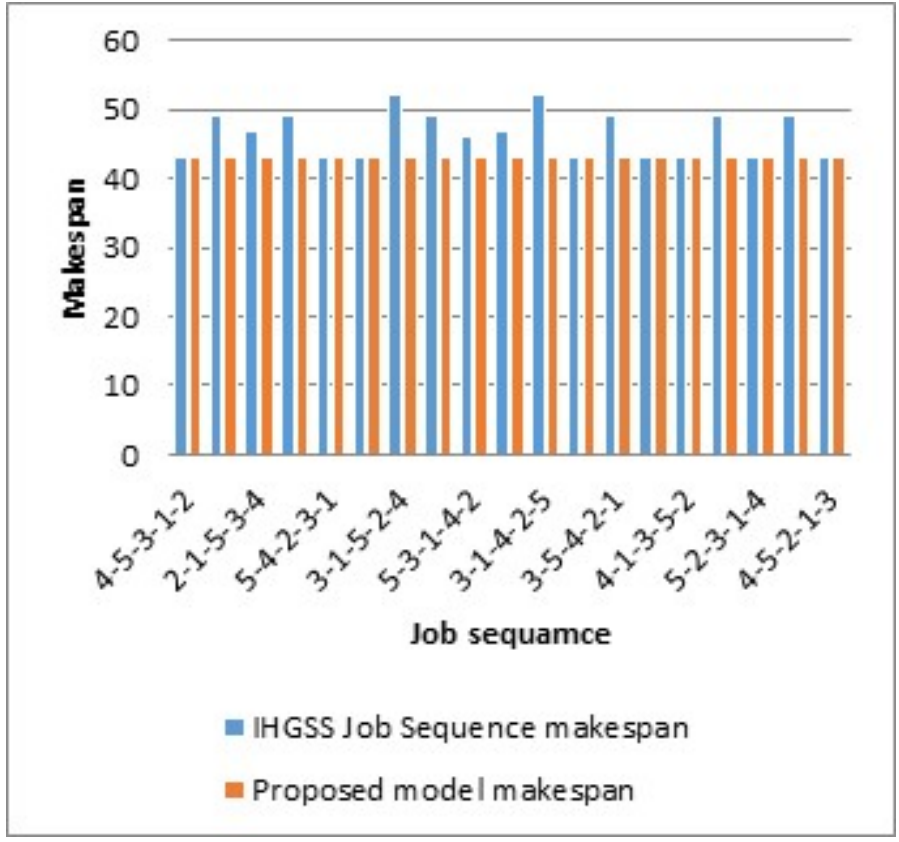

Figure 9: Comparison between different job sequences by IHGSS and proposed model respect to make-span

\section{CASE STUDIES` PERFORMANCE COMPARISON}

In this section, a study of the performance effectiveness of our proposed model compared to benchmarking models is carried out. The percentage improvement in make-span is calculated by relative percentage increase (RPI) that is considered as an indicator of the improvement or retrogression of make-span which is calculated as follows:

$$
R P I=\frac{C_{\text {max }}^{c}-C_{\text {best }}}{C_{\text {best }}} * 100
$$

Where:

$R P I:$ is the \% of improvement in make-span

$C_{\text {max }}^{c}:$ is the current make-span that is compared to the best make-span.

$C_{\text {best }}$ : the best make-span in the whole compared algorithms.

The RPI is applied on the benchmarking make-span and proposed model for each case study. Figure (10a, 10b, 10c, 10d) shows the RPI \% for each benchmarking case studies and the proposed model. As for case study 1 that is shown in Figure (10a), the proposed model shows better other used methods. The RPI for HVNS is about $16.18 \%$, for PSO is about $16.18 \%$, as for AIS is about $17.65 \%$, as for ACO is about $17.65 \%$, and as for B\&B is about $42.64 \%$. As for case study 2 that is shown at Figure (10b) the RPI\% for both RR and SDR is about $31.58 \%$. The case study 3 RPI\% is shown at Figure (10c). The RPI\% for GA is about $47.66 \%$ and for DA is about $27.23 \%$. The case study 4 is shown at Figure (10d). The RPI\% for the job sequence that is solved by IHGSS which are :4-5-2-1-3, 5-2-3-1-4, 4-1-3-5-2, 4-1-2-3-5, 5-1-3-4-2, 
4-5-1-2-3, 5-4-2-3-1, and 4-5-3-1-2 is 0\%. The RPI\% for job sequence that is solved by IHGSS which are: 1-4-5-2-3, 3-4$2-1-5,3-5-4-2-1,1-2-4-5-3$, and 1-2-4-3-5 is about 13.95\%. The RPI\% for job sequence that is solved by IHGSS which are: 3-1-5-2-4 and 3-1-4-2-5 is 20.93\%. The RPI\% for job sequence that is solved by IHGSS which are: 3-1-5-2-4 and 3-14-2-5 is about $20.23 \%$ but for job sequence $5-3-1-4-2$ the RPI\% is about $6.98 \%$.

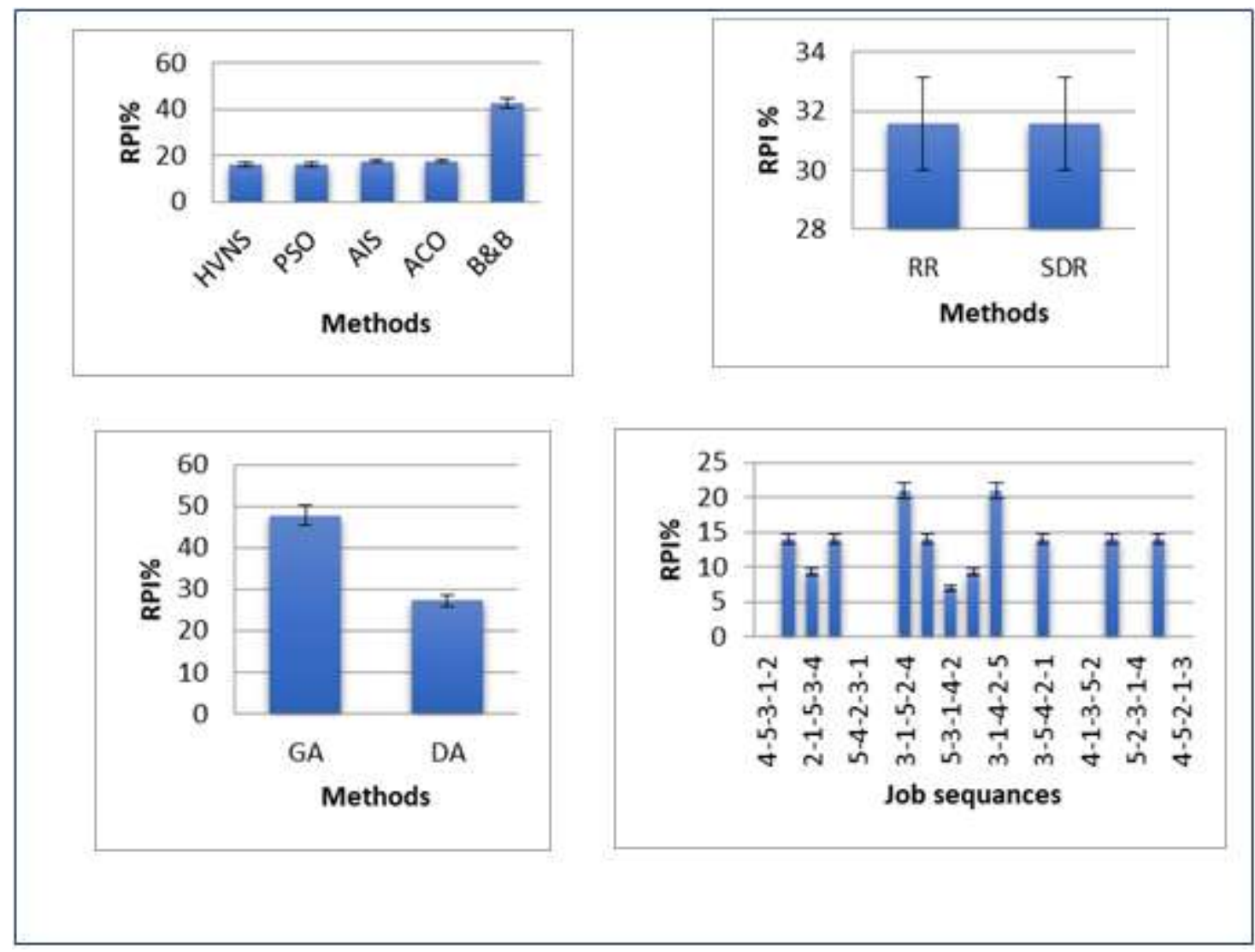

Figure 10: RPI\% comparison for cases studies $(1,2,3$, and 4)

\section{CONCLUSION AND FUTURE WORK}

A hybrid flow-shop with eligible unrelated parallel machines lot streaming (HFSEUPML) was studied in this paper. The nonlinear mixed-integer programming is used to solve the problem of minimization of the make-span for (HSFEUPML) system and determine the optimum number of jobs' sub-lots, size of each sub-lot for each job on each machine among different stages and allocate the sub-lots on the machine to minimize the Cmax. The proposed model is used also to solve a real case in the metal nails manufacturing industry. The results show that there is a reduction of $29.52 \%$ in the make-span by applying the proposed model on the actual case and comparing it with the make-span that the factory adopted. The proposed model was compared to four benchmarking case studies. The results showed that the proposed model is better than the benchmarking.

The future work will be to study the same case and solving it using well known available algorithms to compare the results with the proposed model. It is worth also to study the constraints of both shifting time and machines maintenance to mitigate the real conditions of the workshop. 


\section{REFERENCES}

1. C. Oğuz, Y. Zinder, V. H. Do, A. Janiak, and M. Lichtenstein, 'Hybrid flow-shop scheduling problems with multiprocessor task systems', Eur. J. Oper. Res., vol. 152, no. 1, pp. 115-131, 2004.

2. Y. Y. Chen, C. Y. Cheng, L. C. Wang, and T. L. Chen, 'A hybrid approach based on the variable neighborhood search and particle swarm optimization for parallel machine scheduling problems - A case study for solar cell industry', Int. J. Prod. Econ., vol. 141, no. 1, pp. 66-78, 2013.

3. W. G. Truscott, 'Production scheduling with capacity-constrained transportation activities', Journal of Operations Management, vol. 6, no. 3-4.pp. 333-348, 1986.

4. I. Ribas, R. Leisten, and J. M. Framiñan, 'Review and classification of hybrid flow shop scheduling problems from a production system and a solutions procedure perspective', Computers and Operations Research, vol. 37, no. 8. pp. 1439$1454,2010$.

5. R. Ruiz and J. A. Vázquez-Rodriguez, 'The hybrid flow shop scheduling problem', European Journal of Operational Research, vol. 205, no. 1. pp. 1-18, 2010.

6. T. S. Lee and Y. T. Loong, 'A review of scheduling problem and resolution methods in flexible flow shop', International Journal of Industrial Engineering Computations, vol. 10, no. 1. pp. 67-88, 2019.

7. P. Fattahi, S. M. H. Hosseini, F. Jolai, and R. Tavakkoli-Moghaddam, 'A branch and bound algorithm for hybrid flow shop scheduling problem with setup time and assembly operations', Applied Mathematical Modelling, vol. 38, no. 1. pp. 119-134, 2014.

8. S. K. Paul and A. Azeem, 'MINIMIZATION OF WORK-IN-PROCESS INVENTORY IN HYBRID FLOW SHOP SCHEDULING USING FUZZY LOGIC', vol. 17, no. 2, pp. 115-127, 2010.

9. C. Low, C. Hsu, and C. Su, 'A two-stage hybrid flowshop scheduling problem with a function constraint and unrelated alternative machines', vol. 35, pp. 845-853, 2008.

10. F. Choong and M. Y. Alias, 'Metaheuristic methods in hybrid flow shop scheduling problem', Expert Syst. Appl., vol. 38, no. 9, pp. 10787-10793, 2011.

11. V. Saluja and A. Jain, 'OPTIMIZATION OF FLEXIBLE FLOW SHOP SCHEDULING WITH SEQUENCE DEPENDENT SETUP TIME AND LOT SPLITTING', no. Aimtdr, pp. 1-6, 2014.

12. M. R. A. A and M. A. Beheshti-nia, 'Hybrid flow shop scheduling with parallel batching', Int . J . Production Economics vol. 117. pp. 185-196, 2009.

13. A. Costa, F. A. Cappadonna, and S. Fichera, 'A novel genetic algorithm for the hybrid flow shop scheduling with parallel batching and eligibility constraints', International Journal of Advanced Manufacturing Technology, vol. 75, no. 5-8. pp. 833-847, 2014.

14. J. Q. Li, Q. K. Pan, and F. T. Wang, 'A hybrid variable neighborhood search for solving the hybrid flow shop scheduling problem', Appl. Soft Comput. J., vol. 24, pp. 63-77, 2014.

15. M. Nejati, I. Mahdavi, R. Hassanzadeh, N. Mahdavi-Amiri, and M. Mojarad, 'Multi-job lot streaming to minimize the weighted completion time in a hybrid flow shop scheduling problem with work shift constraint', International Journal of Advanced Manufacturing Technology, vol. 70, no. 1-4. pp. 501-514, 2014.

16. J. L. Lalitha, N. Mohan, and V. M. Pillai, 'Lot streaming in $[N-1](1)+N(m)$ hybrid flow shop', J. Manuf. Syst., vol. 44, pp. 12-21, 2017

17. B. Naderi, R. Ruiz, and M. Zandieh, 'Algorithms for a realistic variant of flowshop scheduling', Comput. Oper. Res., vol. 37, no. 2, pp. 236-246, 2010.

18. B. Naderi and M. Yazdani, 'A model and imperialist competitive algorithm for hybrid flow shops with sublots and setup times', Journal of Manufacturing Systems, vol. 33, no. 4. pp. 647-653, 2014. 
19. T. Uetake, H. Tsubone, and M. Ohba, 'A production scheduling system in a hybrid flow shop', International Journal of Production Economics, vol. 41, no. 1-3. pp. 395-398, 1995.

20. I. L. Wang, T. Yang, and Y. B. Chang, 'Scheduling two-stage hybrid flow shops with parallel batch, release time, and machine eligibility constraints', Journal of Intelligent Manufacturing, vol. 23, no. 6. pp. 2271-2280, 2012.

21. W. Zhang, C. Yin, J. Liu, and R. J. Linn, 'Multi-job lot streaming to minimize the mean completion time in m-1 hybrid flowshops', International Journal of Production Economics, vol. 96, no. 2. pp. 189-200, 2005.

22. O. Shahvari and R. Logendran, 'A comparison of two stage-based hybrid algorithms for a batch scheduling problem in hybrid flow shop with learning effect', Int. J. Prod. Econ., vol. 195, no. July 2017, pp. 227-248, 2018.

23. Y. Zhang, S. Liu, and S. Sun, 'Clustering and genetic algorithm based hybrid flowshop scheduling with multiple operations', Math. Probl. Eng., vol. 2014, no. 2, 2014.

24. S. Voß and A. Witt, 'Hybrid flow shop scheduling as a multi-mode multi-project scheduling problem with batching requirements: A real-world application', International Journal of Production Economics, vol. 105, no. 2. pp. 445-458, 2007.

25. J.L. Hunsucker and J.R. Shah' Comparative performance analysis of priority rules in a constrained flow shop with multiple processors environment', European Journal of Operational Research, vol.72, 1994

26. A. Vignier, J.-C. Billaut, C. Proust, Les 'problFmes d'ordonnancement de type flow-shop hybride: Ttat de l'art', RAIRO Recherche OpTrationnelle 33 (2)

27. B. Zhang, Q. ke Pan, L. Gao, X. li Zhang, H. yan Sang, and J. qing Li, 'An effective modified migrating birds optimization for hybrid flowshop scheduling problem with lot streaming', Appl. Soft Comput. J., vol. 52, pp. 14-27, 2017.

28. Y. Xu and L. Wang, 'Differential evolution algorithm for hybrid flow-shop scheduling problems', J. Syst. Eng. Electron., vol. 22, no. 5, pp. 794-798, 2011.

29. M. K. Marichelvam and T. Prabaharan, 'Performance evaluation of an improved hybrid genetic scatter search (IHGSS) algorithm for multistage hybrid flow shop scheduling problems with missing operations', Int. J. Ind. Syst. Eng., vol. 16 , no. 1, pp. 120-141, 2014. 
